\title{
Application of loop-mediated isothermal amplification combined with colorimetric and lateral flow dipstick visualization as the potential point-of-care testing for Corynebacterium diphtheriae
}

\author{
Aleksandra A. Zasada*, Aldona Wiatrzyk, Urszula Czajka, Klaudia Brodzik, Kamila Formińska, Ewa Mosiej, \\ Marta Prygiel, Katarzyna Krysztopa-Grzybowska and Karol Wdowiak
}

\begin{abstract}
Background: Diphtheria outbreaks occurred in endemic areas and imported and indigenous cases are reported in UE/EEA. Because of the high infectiveness and severity of the disease, early and accurate diagnosis of each suspected case is essential for the treatment and management of the case and close contacts.

The aim of the study was to establish simple and rapid testing methods based on Loop-Mediated Isothermal Amplification (LAMP) assay for the detection of Corynebacterium diphtheriae and differentiation between toxigenic and non-toxigenic strains.

Methods: Corynebacterium diphtheriae and Corynebacterium ulcerans isolates from the National Institute of Public Health-National Institute of Hygiene collection were used for the development of LAMP assay for the diagnosis of diphtheria and nontoxigenic C. diphtheriae infections. Various colorimetric methods for visualization of results were investigated. Sensitivity and specificity of the assay were examined using a collection of DNA samples from various gram-positive and gram-negative bacteria.

Results: The LAMP assay for tox and $d t x R$ genes was developed. The sensitivity and specificity of the assay were calculated as $100 \%$. The detection limit was estimated as $1.42 \mathrm{pg} / \mu \mathrm{l}$ concentration of DNA template when the reaction was conducted for $60 \mathrm{~min}$. However, the detection limit was lowered 10 times for every $10 \mathrm{~min}$ of reduction in the time of incubation during the reaction. Positive results were successfully detected colorimetrically using hydroxynaphthol blue, calcein, QuantiFluor, and lateral flow Milenia HybriDetect dipsticks.
\end{abstract}

Conclusion: The assay developed in the study might be applied for point-of-care testing of diphtheria and other $C$. diphtheriae infections as well as for other infections caused by diphtheria-toxin producing Corynebacterium species. It is highly sensitive, specific, inexpensive, easy to use, and suitable for low-resource settings.

Keywords: LAMP, POCT, Diphtheria, Corynebacterium diphtheriae, Colorimetric detection, Lateral flow dipstick

\footnotetext{
*Correspondence: azasada@pzh.gov.pl

Department of Sera and Vaccines Evaluation, National Institute of Public

Health - National Institute of Hygiene, Chocimska 24, 00-791 Warsaw, Poland
}

(c) The Author(s). 2020 Open Access This article is licensed under a Creative Commons Attribution 4.0 International License, which permits use, sharing, adaptation, distribution and reproduction in any medium or format, as long as you give appropriate credit to the original author(s) and the source, provide a link to the Creative Commons licence, and indicate if changes were made. The images or other third party material in this article are included in the article's Creative Commons licence, unless indicated otherwise in a credit line to the material. If material is not included in the article's Creative Commons licence and your intended use is not permitted by statutory regulation or exceeds the permitted use, you will need to obtain permission directly from the copyright holder. To view a copy of this licence, visit http://creativecommons.org/licenses/by/4.0/. The Creative Commons Public Domain Dedication waiver (http://creativecommons.org/publicdomain/zero/1.0/) applies to the data made available in this article, unless otherwise stated in a credit line to the data. 


\section{Background}

Diphtheria is an acute, highly infectious and potentially lethal infectious disease of humans. The disease is caused by diphtheria toxin-producing strains of Corynebacterium diphtheriae, Corynebacterium ulcerans, and Corynebacterium pseudotuberculosis. The infection can be transmitted through contact with infected persons and objects that are touched by them. The disease could be presented as respiratory or cutaneous diphtheria, depending on the anatomic site that is affected by the toxigenic corynebacteria. Rarely other sites can also be affected such as ear, eye, and vulva. Diphtheria toxin absorbed from the mucosal or cutaneous lesions causes toxic damage to the nervous system, myocardium and kidneys. In respiratory diphtheria cases, formed pseudomembranes can cause obstruction in the airways [1].

The infections caused by toxigenic corynebacteria seemed to be well controlled in developed countries since the introduction of vaccination against diphtheria in the 1940s. But, infections recorded during the last several years point at $C$. diphtheriae and $C$. ulcerans as reemerging human pathogens. According to ECDC data, the number of confirmed diphtheria cases in EU/EEA increased over three times from 2011 to 2015 [2]. Domestic pets and other animals have been described as novel reservoirs and sources of diphtheria infection [35]. Moreover, diphtheria is endemic in many countries in Asia, the South Pacific, the Middle East, and Eastern Europe and in Haiti and the Dominican Republic; outbreaks in Indonesia, Thailand, Laos, South Africa, Sudan, and Pakistan have occurred since 2011 [6]. According to WHO data, 28,358 cases of diphtheria were recorded between 2012 and 2016 worldwide. In the period 20122016, India had the largest total number of reported cases each year, with a 5-year total of 17,497 cases, followed by Indonesia and Madagascar with 2739 and 4492 reported cases, respectively [7]. In addition, the diphtheria cases were described in asylum seekers in Europe $[8,9]$. In Poland, the last diphtheria case was recorded in 2000. But in 2004 the first case of sepsis caused by nontoxigenic $C$. diphtheriae was recorded and since then increasing number of nontoxigenic $C$. diphtheriae infections, including invasive infections, has been recorded every year [10, 11].

Because of the high infectiveness and severity of the disease, early and accurate diagnosis of each suspected case is essential for the treatment and management of the case and close contacts. Rapid microbiological tests are of high value because clinical diagnosis is not easy and might be confused with other causes, such as streptococcal sore throat or tonsillitis [12]. Misdiagnosis is the high risk particularly in countries where the diphtheria is uncommon. Gap analysis on securing diphtheria diagnostic capacity in the EU/EEA revealed that $3 \%$ of
EU Member States have minimum or no diagnostic capability and $17 \%$ have only partial diagnostic capability [12]. Point-of-care diphtheria testing is especially important in refugee camps and developing countries, where access to medical laboratories is extremely limited as well as in the investigation of an infection source.

Our study aimed to establish simple and rapid testing methods based on LAMP assay for the detection of $C$. diphtheriae and differentiation between toxigenic and non-toxigenic strains as well as detection of other infections caused by diphtheria-toxin producing Corynebacterium species. Additionally, we compared various methods for visualization of amplified products. We decided to apply LAMP technology because it enables efficient DNA amplification under isothermal conditions. To find the optimal method for amplicon detection we compared commercially available lateral flow dipsticks and cheaper colorimetric methods with various dyes.

\section{Methods \\ Bacterial strains and DNA extraction}

A total of 51 bacterial strains were used in the study, including 9 toxigenic and 31 nontoxigenic Corynebacterium strains and 11 strains of other bacterial species that might be present in the respiratory tract. The toxigenic strains included $5 \mathrm{C}$. diphtheriae clinical isolates, one $C$. ulcerans clinical isolate, and reference $C$. diphtheriae strains such as PW8, NCTC 10648, and NCTC 3984. The nontoxigenic strains included $30 \mathrm{C}$. diphtheriae clinical isolates and the reference $C$. diphtheriae strain NCTC 10356. Other bacterial species that might be present in the respiratory tract included Streptococcus salivarius, Streptococcus pneumoniae, Streptococcus pyogenes, Streptococcus epidermidis, Haemophilus influenzae, Moraxella catarrhalis, Staphylococcus aureus, Corynebacterium pseudodiphtheriticum, Pseudomonas aeruginosa, Escherichia coli, and Klebsiella pneumoniae.

DNA extraction was performed for $24 \mathrm{~h}$ bacterial cultures on the medium appropriate for the bacterial species by using DNeazy Blood and Tissue Kit (Qiagen, Germany) according to the manufacturer's instructions for Grampositive and Gram-negative bacteria, respectively.

\section{Bacteria identification}

Corynebacterium strains were identified and biotyped based on the colony morphology on tellurite agar plates and ApiCoryne tests (Biomerieux, France). Toxigenicity was tested using Elek test. Additionally, the presence of tox gene was verify by PCR, according to WHO Manual for Laboratory Diagnosis of Diphtheria [13].

Other non-Corynebacterium strains mentioned above were identified using conventional microbiology methods, including appropriate selective media, Gram-staining and biochemical tests. 
Loop-mediated isothermal amplification (LAMP)

LAMP primer sets for the detection of tox gene coding diphtheria toxin and $d t x R$ gene coding global regulator were designed by using LAMP designer software PrimerExplorer V4 (https://primerexplorer.jp/e/) based on the nucleotide sequence of the $C$. diphtheriae NCTC 13129 whole genome, available from GenBank under the number BX248353. Each LAMP primer set included two outer (F3, B3), two inner (FIB, BIP), and two loop primers (LF, LB). The sequences of the oligonucleotide primer sets used in the study are presented in Table 1. For the detection of amplified products using the lateral flow dipsticks, the FIB and BIP primers were labeled with biotin and fluorescein isothiocyanate (FITC), respectively, at the $5^{\prime}$ end. For the colorimetric detection of amplified products, unmodified primers were used. Modified primers were obtained from Metabion (Germany) and unmodified primers were obtained from Genomed (Poland). LAMP was carried out in a final reaction volume of $25 \mu \mathrm{l}$. The concentration of primers in the reaction mixture was optimized for each target individually. Finally, the reaction mixture for both targets contained $0.8 \mu \mathrm{M}$ of FIB and BIP primers each, $0.2 \mu \mathrm{M}$ of F3 and B3 primers each, $0.4 \mu \mathrm{M}$ of LF and LB primers each, $1 \times$ reaction buffer containing $20 \mathrm{mM}$ Tris- $\mathrm{HCl}, 50 \mathrm{mM}$ $\mathrm{KCl}, 10 \mathrm{mM}\left(\mathrm{NH}_{4}\right)_{2} \mathrm{SO}_{4}, 2 \mathrm{mM} \mathrm{MgSO}, 0.1 \%$ Tween 20 (New England Biolabs, USA), $0.2 \mathrm{mM}$ dNTP (Sigma-Aldrich, USA), $0.2 \mathrm{M}$ betaine (Sigma-Aldrich, USA), 8 units Bst 2.0 DNA Polymerase (New England Biolabs, USA), and $2 \mu \mathrm{l}$ sample DNA. The reaction was optimized at the temperature ranging from $62{ }^{\circ} \mathrm{C}$ to $70^{\circ} \mathrm{C}$ and conducted for $60 \mathrm{~min}$. During the optimization step, the results of the reaction were analyzed using agarose gel electrophoresis.

\section{Detection of product amplification with the lateral flow dipsticks}

Milenia HybriDetect dipsticks (Milenia Biotec, Germany) were used for the detection of the amplified products labeled with biotin and FITC. Ten microliters of the reaction mixture were pipetted directly on the sample application area on the dipstick. Then, the dipstick was placed with the same application area into $100 \mu \mathrm{l}$ of HybriDetect assay buffer and incubated for 5-15 min in an upright position. The results were regarded as positive when two bands were visible (a control band and a test band) or as negative when only a control band was visible.

\section{Colorimetric detection of amplified products}

For the colorimetric detection of amplified products, 5 indicators were used comparatively: neutral red, phenol red, hydroxynaphthol blue (HNB), calcein and QuantiFluor. Neutral red and phenol red are $\mathrm{pH}$ indicators. They are added to the pre-reaction solution. The progress of LAMP reaction is related to lowering of the solution $\mathrm{pH}$, which can be observed directly as color change of faint orange to pink (neutral red) or red to yellow (phenol red) [14]. Hydroxynaphthol blue and calcein are metal ion indicators. They are also added to the pre-reaction solution. When $\mathrm{Mg}^{2+}$ ion concentration decreases in the progress of LAMP reaction, the color change of the indicators can be observed directly [15]. The color shift is violet to blue for HNB and orange to fluorescent green for calcein. QuantiFluor is a DNA intercalating dye. It is added to the solution after the reaction is completed. When the LAMP reaction is positive, a color change of orange to fluorescent yellow is observed under ambient light condition.

Neutral red (Sigma-Aldrich, USA) and phenol red (Sigma-Aldrich, USA) were dissolved in deionized water or $1 \mathrm{M} \mathrm{NaOH}$, respectively, at $50 \mathrm{mM}$ to prepare a stock solution and diluted to $2.5 \mathrm{mM}$. For the optimization of the concentration of the indicators in the reaction solution, the following final concentrations were tested: 0.2, $0.15,0.1,0.05$, and $0.01 \mathrm{mM}$. HNB was dissolved in

Table 1 LAMP primers used in the study

\begin{tabular}{|c|c|c|}
\hline Target gene & Name & Sequence $\left(5^{\prime} \rightarrow 3^{\prime}\right)$ \\
\hline \multirow[t]{6}{*}{ tox } & LF-toxIII & GCATAGTTAGCCCCAGCGAAT \\
\hline & LB-toxIII & ACTTCCTGGTATCGGTAGCGT \\
\hline & F3-toxlll & CGGCATTAGAGCATCCTG \\
\hline & B3-toxIII & CTAGCTCTCCTACCAATGGA \\
\hline & FIP-toxIII & CGCAACGTTTACTGCCCATTTCTTACTGGGACCAATCCTGT \\
\hline & BIP-tox|II & AAGACAACTGCTGCTCTIIITITCGATATTGTGGTGAACGGCAC \\
\hline \multirow[t]{6}{*}{$d t \times R$} & LF-dtxRIII & TCGTCACTCATAACGTGTTCC \\
\hline & LB-dtxRIII & CGGCGTAGGCAATTCTGA \\
\hline & F3-dtxRIII & AACATCGCTTAGCTGAGC \\
\hline & B3-dtxRIII & CGTTAATCTGAACAATGCGTAC \\
\hline & FIP-dtxRIII & TTCACGAGCCTGCGTTCTTTTAAAAGTTCACGATGAAGCCTG \\
\hline & BIP-dtxRIII & CAATTCCAGGTCTCGACTITTGAACTTCAATAACGCGAGTTCCG \\
\hline
\end{tabular}


deionized water at $50 \mathrm{mM}$ to prepare a stock solution. Then, the solution was diluted and tested in the LAMP reaction at the following final concentrations: $1,0.5$, $0.32,0.25,0.16,0.125,0.08$, and $0.04 \mathrm{mM}$. The calcein stock solution consisted of $0.5 \mathrm{mM}$ calcein (Novazym, Poland) and $10 \mathrm{mM} \mathrm{MnCl}_{2}$ (Sigma-Aldrich, USA) in deionized water. To select an optimal concentration, the following volumes of the stock solution were added to the reaction solution: $0.25,0.5,1,1.5$, and $2 \mu \mathrm{l}$. The amount of QuantiFluor (Promega, Germany) in the post-reaction solution was optimized by the addition of the following volumes of the dye: 2,1 , and $0.5 \mu \mathrm{l}$.

\section{Determination of specificity, sensitivity, detection limit, and minimal reaction time}

Specificity and sensitivity of the LAMP were investigated using abovementioned bacterial species that can be present in respiratory tracts. The sensitivity was calculated as follows: $\mathrm{A} /(\mathrm{A}+\mathrm{C}) \times 100 \%$, and the specificity was calculated as follows: $D /(B+D) \times 100 \%$, where $A$ is the number of true positive results, $B$ is the number of false-positive results, $\mathrm{C}$ is the number of false-negative results, and $\mathrm{D}$ is the number of true negative results. Additionally, positive (PPV) and negative predictive value (NPV) were calculated as follows: $\mathrm{PPV}=\mathrm{A} /(\mathrm{A}+\mathrm{B})$ $\times 100 \%, \mathrm{NPV}=\mathrm{D} /(\mathrm{C}+\mathrm{D}) \times 100 \%$. Accuracy of the test was calculated as $(\mathrm{A}+\mathrm{D}) /(\mathrm{A}+\mathrm{B}+\mathrm{C}+\mathrm{D}) \times 100 \%$. The gold standard was conventional microbiological methods of bacteria identification described above.

The limit of detection was investigated using 10-fold serial dilutions of the total genomic DNA.

To determine required minimal LAMP reaction time, we examined the results of the reactions for tox and $d t x R$ markers after 10, 20, 30, 40, 50, and 60 min of incubation using 10-fold serial dilutions of the total genomic DNA as a reaction template.

\section{Results}

The species-specific $d t x R$ gene present in all C. diphtheriae strains and the tox gene present only in potentially toxigenic C. diphtheriae, C. ulcerans, and C. pseudotuberculosis strains were selected as target genes for designing the LAMP primers. Initially, three sets of primers for each of the genetic markers investigated were designed but only the sets presented in Table 1 did not yield false-positive results and therefore were selected for the study. The concentration of each of the primer as well as other reagents in the reaction mixture was optimized. Labeling of the primers FIB and BIP with biotin and FITC did not influence the amplification reaction, as it was assessed based on agarose gel electrophoresis results. The efficiency of the LAMP reaction was comparable in the temperature ranging from $62^{\circ} \mathrm{C}$ to $70^{\circ} \mathrm{C}$ (Fig. 1). For the study, we selected $65^{\circ} \mathrm{C}$ as

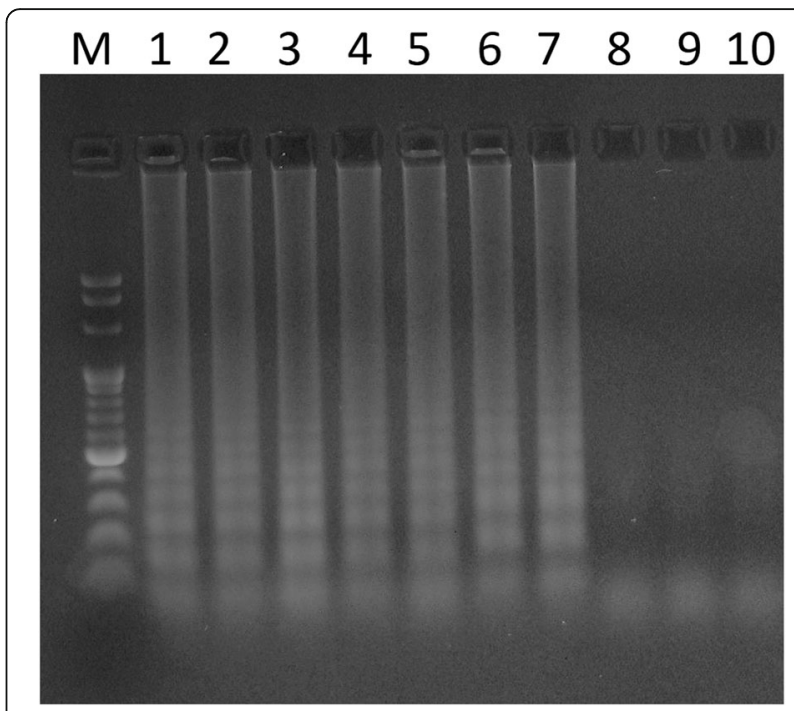

Fig. 1 Agarose gel electrophoresis of products of the LAMP reaction for tox gene conducted for $60 \mathrm{~min}$ at various temperatures. M-Molecular Ladder, lane 1 -incubation at $62^{\circ} \mathrm{C}$, lane 2 -incubation at $64^{\circ} \mathrm{C}$, lane 3 -incubation at $65^{\circ} \mathrm{C}$, lane 4 -incubation at $66^{\circ} \mathrm{C}$, lane 5 -incubation at $67^{\circ} \mathrm{C}$, lane 6 -incubation at $68^{\circ} \mathrm{C}$, lane 7 -incubation at $70^{\circ} \mathrm{C}$, and lanes 8-10-negative controls

recommended by the manufacturer of the Bst 2.0 DNA polymerase.

We could detect positive LAMP reactions with the naked eye using HNB, calcein, QuantiFluor, and Milenia HybriDetect dipsticks. The positive reaction was clearly visible when the used HNB concentration was 0.125 , 0.16 , and $0.25 \mathrm{mM}$. For further studies, we selected the concentration $0.16 \mathrm{mM}$ of HNB. The optimal amounts of calcein and QuatiFluor per reaction were 0.5 and $2 \mu \mathrm{l}$, respectively (Table 2). By using Milenia HybriDetect dipsticks, we observed atypical results for samples with a high concentration of DNA. According to manufacturer's instructions, two color bands should be visible on the dipstick for positive results: test band and control band, whereas only control band should be visible for negative results. However, we observed that when the concentration of amplicons was high, the control band was not visible (Fig. 2). This issue was overcome by the dilution of the amplified product. We could not detect positive LAMP reaction when the neutral red and phenol red were used. It was probably because the $\mathrm{pH}$ changes during the reaction were very subtle.

The sensitivity and specificity of the LAMP reaction for tox and $d t x R$ markers were comparable using HNB, calcein, and QuantiFluor, as well as Milenia HybriDetect dipsticks, and both were calculated as 100\%. PPV, NPV and accuracy were also 100\% (Table 3 and Table 4). The detection limit was also comparable for both genetic markers and all product detection methods and 
Table 2 Comparison of the optimal concentration of various indicators for colorimetric detection of LAMP results

\begin{tabular}{lllllllllll}
\hline Indicatior & \multicolumn{10}{l}{ Concentration $(\mathrm{mM})$} \\
\cline { 2 - 11 } & 2 & 1.5 & 1 & 0.5 & 0.32 & 0.25 & 0.16 & 0.125 & 0.08 & 0.04 \\
\hline HNB & - & $\mathrm{nt}$ & - & - & - & + & + & + & - & - \\
calcein & - & - & - & + & $\mathrm{nt}$ & - & $\mathrm{nt}$ & $\mathrm{nt}$ & $\mathrm{nt}$ & $\mathrm{nt}$ \\
QuantiFluor & + & $\mathrm{nt}$ & - & - & $\mathrm{nt}$ & $\mathrm{nt}$ & $\mathrm{nt}$ & $\mathrm{nt}$ & $\mathrm{nt}$ & $\mathrm{nt}$ \\
\hline
\end{tabular}

nt not tested

estimated as $1.42 \mathrm{pg} / \mu \mathrm{l}$ concentration of DNA template, which means $2.84 \mathrm{pg}$ of DNA in $25 \mu \mathrm{l}$ of the reaction mixture, when the reaction was conducted for $60 \mathrm{~min}$. However, the detection limit lowered 10 times for every 10 min of reduction in the time of incubation during the reaction (Table 5, Fig. 3 ).

\section{Discussion}

Diphtheria is a vaccine-preventable disease. Currently, the diphtheria vaccination coverage varied from $42 \%$ in some developing countries to $99 \%$ in some developed countries [16]. Diphtheria outbreaks occur in endemic countries, and diphtheria cases are reported every year in EU/EEA. According to ECDC data, 216 diphtheria cases were reported in EU/EEA in the period 2012-

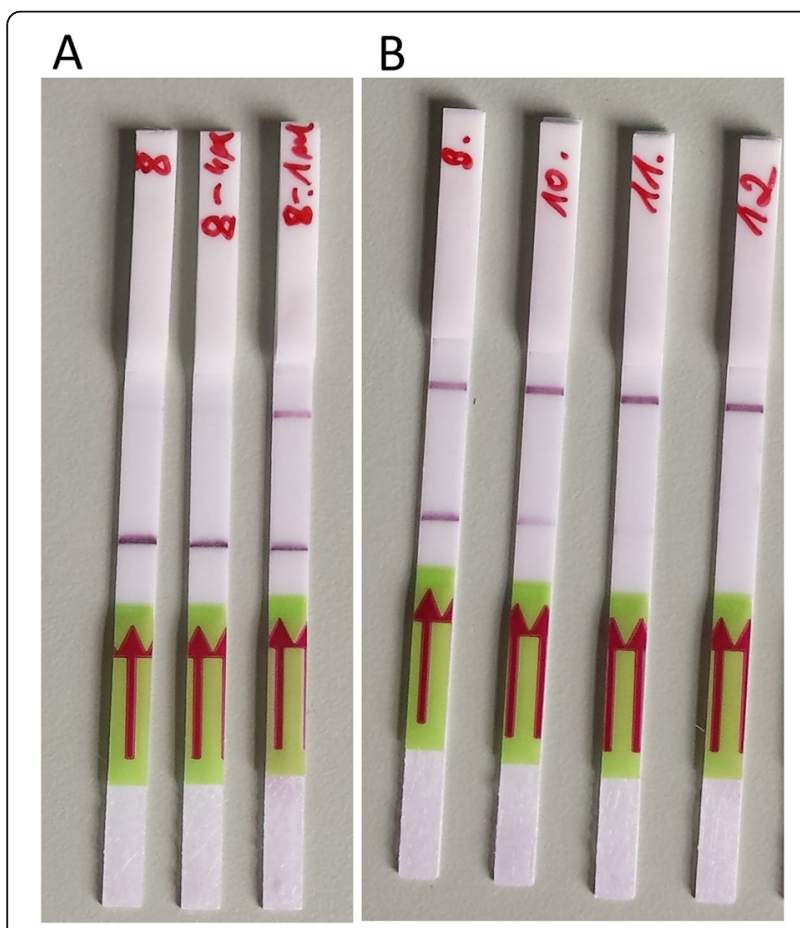

Fig. 2 Visualization of LAMP for $d t x R$ gene using lateral flow dipsticks. A lower band indicates positive results of the amplification. A higher band is a control of the lateral flow test. A high concentration of amplified products may cause lack of a control band. $\mathbf{a}$-serial dilutions of the amplified product; $\mathbf{b}$ - -serial dilutions of the DNA sample
Table 3 Results of the LAMP for tox gene and $d t x R$ gene for various DNA samples

\begin{tabular}{lll}
\hline Bacterial species (number of strains tested) & \multicolumn{2}{l}{ LAMP results } \\
\cline { 2 - 3 } & tox & $d t x R$ \\
\hline Toxigenic Corynebacterium diphtheriae (8) & + & + \\
Non-toxigenic Corynebacterium diphtheriae (31) & - & + \\
Toxigenic Corynebacterium ulcerans (1) & + & - \\
Streptococcus salivarius (1) & - & - \\
Streptococcus pneumoniae (1) & - & - \\
Streptococcus pyogenes (1) & - & - \\
Streptococcus epidermidis (1) & - & - \\
Haemophilus influenzae (1) & - & - \\
Moraxella catharalis (1) & - & - \\
Staphylococcus aureus (1) & - & - \\
Corynebacterium pseudodiphtheriticum (1) & - & - \\
Pseudomonas aeruginosa (1) & - & - \\
Escherichia coli (1) & - & - \\
Klebsiella pneumoniae (1) & - & - \\
\hline
\end{tabular}

2016. Most of them were imported from endemic geographical areas and some were indigenous cases [17]. Moreover, there have been many cases being described involving $C$. diphtheriae and C. ulcerans, which do not fit the WHO definition of diphtheria. These cases include serious invasive infection with high mortality rates caused by nontoxigenic strains of $C$. diphtheriae as well as cutaneous infections, such as non-healing ulcers, caused by toxigenic and non-toxigenic $C$. diphtheriae [10, 11, 17-19], whereas WHO diphtheria case definition cover only an illness of the upper respiratory tract characterized by the following: pharyngitis, nasopharyngitis, tonsillitis or laryngitis and adherent pseudomembrane of the pharynx, tonsils, larynx and/or nose [20].

Epidemiological data on diphtheria and a growing problem of nontoxigenic $C$. diphtheriae invasive infections have revealed the need for point-of-care testing (POCT) technology for the detection of $C$. diphtheriae in carriers, suspected cases, and contacted persons. Such POCT technology would be of great value especially in endemic regions of the disease, where access to health care is limited, and in refugee camps, to timely start appropriate treatment and further prevent the spread of the $C$. diphtheriae and the outbreak. In our study we developed simple and rapid testing methods based on LAMP assay for the detection of $C$. diphtheriae and differentiation between toxigenic and non-toxigenic strains. The developed method was highly sensitive and specific and showed a very low detection limit. It was reported by other researchers that LAMP detection limit is 100 1000 times lower than polymerase chain reaction (PCR) [21]. However, we found that the incubation time 
Table $42 \times 2$ contingency table for tests developed in the study. A - detection of tox gene, B - detection of $d t x R$

\begin{tabular}{|c|c|c|c|c|}
\hline \multirow[t]{2}{*}{ A } & & \multicolumn{3}{|l|}{ Gold standard } \\
\hline & & Positive & Negative & Measures \\
\hline \multirow[t]{3}{*}{ Test results } & Positive & 9 & 0 & $\begin{array}{l}\text { PPV } \\
9 /(9+0) \times 100 \%=100 \%\end{array}$ \\
\hline & Negative & 0 & 42 & $\begin{array}{l}\text { NPV } \\
42 /(0+42) \times 100 \%=100 \%\end{array}$ \\
\hline & Measures & $\begin{array}{l}\text { Sensitivity } \\
9 /(9+0) \times 100 \% \\
=100 \%\end{array}$ & $\begin{array}{l}\text { Specificity } 42 /(0+42) \times 100 \% \\
=100 \%\end{array}$ & $\begin{array}{l}\text { Accuracy } \\
(9+42) /(9+0+0+42) \times 100 \%=100 \%\end{array}$ \\
\hline \multirow[t]{2}{*}{ B } & & Gold standard & & \\
\hline & & Positive & Negative & Measures \\
\hline \multirow[t]{3}{*}{ Test results } & Positive & 39 & 0 & $\begin{array}{l}\text { PPV } \\
39 /(39+0) \times 100 \%=100 \%\end{array}$ \\
\hline & Negative & 0 & 12 & $\begin{array}{l}\text { NPV } \\
12 /(0+12) \times 100 \%=100 \%\end{array}$ \\
\hline & Measures & $\begin{array}{l}\text { Sensitivity } \\
39 /(39+0) \times 100 \%=100 \%\end{array}$ & $\begin{array}{l}\text { Specificity } \\
12 /(0+12) \times 100 \%=100 \%\end{array}$ & $\begin{array}{l}\text { Accuracy } \\
(39+12) /(39+0+0+12)=100 \%\end{array}$ \\
\hline
\end{tabular}

necessary to obtain positive results depends on the amount of the target DNA in the sample. The methods of visualization the results, including the use of $\mathrm{HNB}$, QuantiFluor, calcein, and Milenia HybriDetect dipsticks, did not influence the detection limit, but colorimetric detection using HNB and calcein, which were added to the reaction mixture before incubation, are superior to QuantiFluor and Milenia HybriDetect dipsticks because they enable faster detection of positive reaction in the real-time mode, and no additional handling after reaction is needed. The opening tubes after the reaction is associated with an increased risk of contamination of other subsequent LAMP reaction solutions. On the other hand, differences in transparency of various plastic tubes might influence on readability of color change. Moreover, color interpretation can be subjective.

Regardless of the visualization method used, it must be kept in mind that a small percentage of strains are tox gene positive but do not produce active toxin [22, 23]. Therefore, strains positive for tox should subsequently be tested by the Elek test for expression of diphtheria toxin.
The LAMP reaction temperature ranging from $62^{\circ} \mathrm{C}$ to $70{ }^{\circ} \mathrm{C}$, as revealed in our study, shows that the heating device used does not have to be very precise. Hatano et al. [24] proposed the conduction of LAMP using a disposable pocket warmer placed in a Styrofoam box. It makes the LAMP assay independent from any electric power and therefore applicable in sites where electricity infrastructures are inadequate, such as undeveloped areas. LaBarre et al. [25] developed the noninstrumented nucleic acid amplification heater suitable for isothermal amplification methods, where heat is generated by an exothermic reaction of $\mathrm{CaO}$ with water. Cost of the LAMP assay proposed in our study is 2-25 euros per 50 samples tested (depending from the selected dye) when colorimetric visualization is used and about 120 euros per 50 samples when the dipstick visualization is used. The assay is fairly cost-effective when combined with colorimetric visualization with HNB and calcein. The QuantiFluor is more expensive and increases the cost of testing.

One of the disadvantages of most molecular methods is the requirement for storage conditions of reagents,

Table 5 Results of examination the minimal incubation time required for the LAMP assay when various concentrations of DNA template have been used

\begin{tabular}{|c|c|c|c|c|c|c|}
\hline \multirow{2}{*}{$\begin{array}{l}\text { Incubation } \\
\text { time (min) }\end{array}$} & \multicolumn{5}{|c|}{ DNA dilution (used as a template) } & \multirow{2}{*}{$\begin{array}{l}\text { Negative } \\
\text { control }\end{array}$} \\
\hline & $1.42 \mathrm{ng} / \mu \mathrm{l}$ & $142 \mathrm{pg} / \mu \mathrm{l}$ & $14.2 \mathrm{pg} / \mu \mathrm{l}$ & $1.42 \mathrm{pg} / \mu \mathrm{l}$ & $142 \mathrm{fg} / \mu \mathrm{l}$ & \\
\hline 10 & - & - & - & - & - & - \\
\hline 20 & - & - & - & - & - & - \\
\hline 30 & + & - & - & - & - & - \\
\hline 40 & + & + & - & - & - & - \\
\hline 50 & + & + & + & - & - & - \\
\hline 60 & + & + & + & + & - & - \\
\hline
\end{tabular}



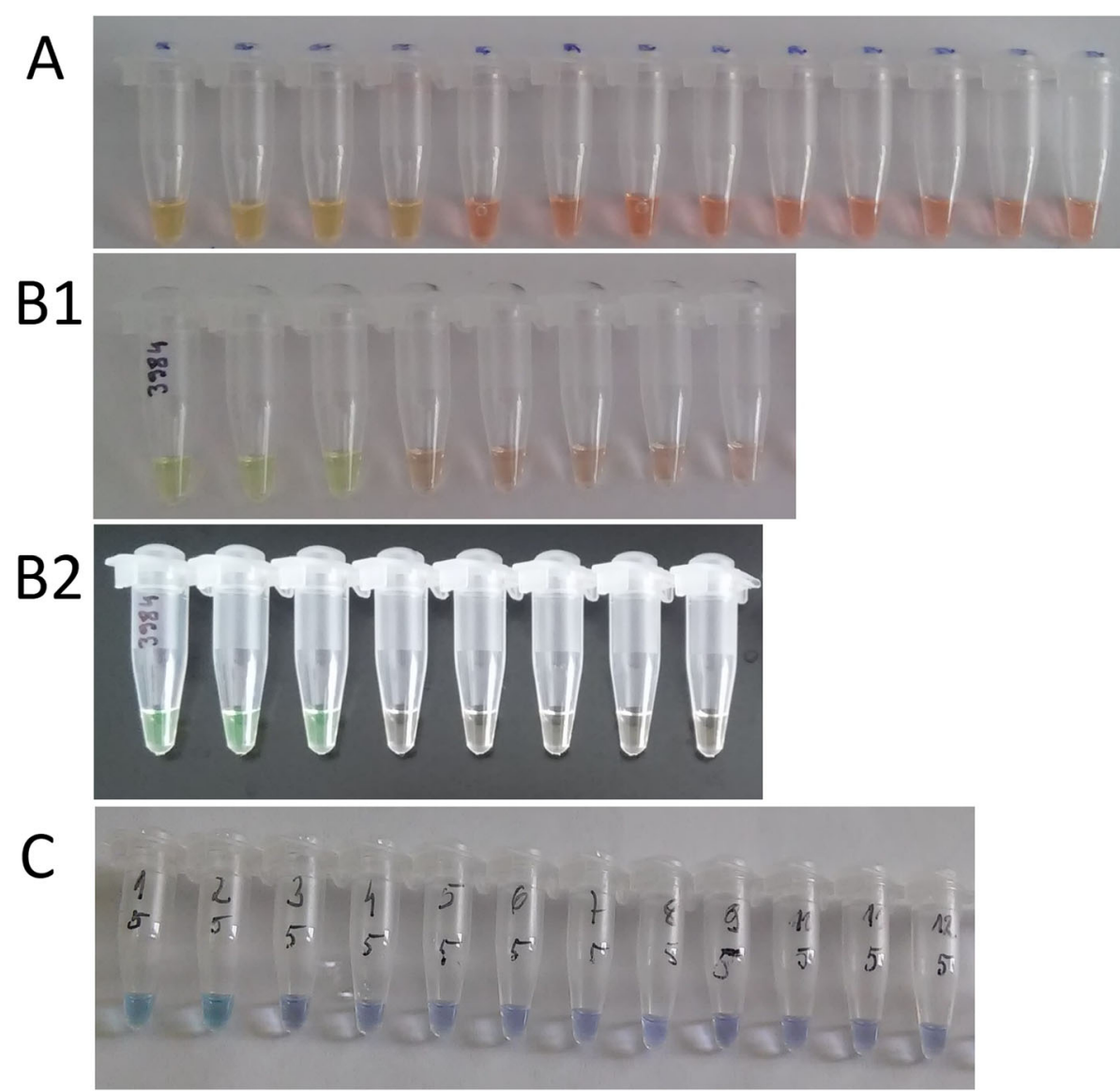

Fig. 3 Results of the LAMP detection limit for tox gene. From the left to the right, 10-fold serial dilutions of the DNA samples. A-60 min of incubation, detection using QuantiFluor; B-50 min of incubation, detection using calcein (B1—white background, B2—black background); C-40 min of incubation, detection using HNB

such as polymerases, which usually have to be kept in freezing. However, a lyophilized mastermix containing all reagents required for LAMP assay was developed for the detection of some other pathogens $[25,26]$. Furthermore, LAMP reagents are commercially available in a dry format currently, which can be stored at room temperature.

At the stage of development of the potential point-ofcare test for diphtheria, we used DNA samples. However, according to Yan et al. [27] and Dugan et al. [28], the LAMP assay can be conducted directly from the bacterial colony, as high temperature causes the leak of bacterial cells, after which a high amount of DNA is released. Therefore, our test might be validated to be used for clinical samples directly. It was confirmed that LAMP assay was less affected by various components of clinical samples compared to other molecular methods, such as PCR [27, 29], and therefore, the DNA samples do not have to be purified perfectly. Though, the assays proposed in the study should be validated further using matrices which might contain inhibitors, such as sputum, and real clinical samples.
The limitation of the study is a limited number of non-target bacterial species tested. Based on the other studies and genome sequences available in GenBank the tox and $d t x R$ markers are specific. Nevertheless, the proposed LAMP assay should be tested using more strains of other species, with a special focus on Corynebacterium genus.

\section{Conclusions}

The developed LAMP for diphtheria diagnostics might be a valuable tool for outbreak investigations, especially in endemic areas, as well as for rapid screening of travelers coming from diphtheria-endemic regions. It can also be used for the examination of carriers and diphtheria contact persons. The selection of $d t x R$ gene, apart from tox gene, as a diagnostic marker enables also the detection of non-toxigenic $C$. diphtheriae strains in tested samples, which is important in countries where nontoxigenic $C$. diphtheriae invasive infections are reported [10,18]. 
The assay developed in the study has the potential to be integrated into a diagnostic mobile device for POCT of diphtheria and other $C$. diphtheriae infections, which will be highly sensitive, specific, inexpensive, easy to use, and applicable in low-resource settings. Although our study revealed high specificity and sensitivity and low limit detection of the assay, it should be tested using real clinical samples directly. Future endeavors would include applying these technologies to clinical materials.

\section{Abbreviations}

LAMP: Loop-Mediated Isothermal Amplification; HNB: Hydroxynaphthol blue; POCT: Point-of-care testing; EU/EEA: European Union/European Economic Area

\section{Acknowledgments}

Not Applicable.

\section{Authors' contributions}

AAZ designed the study, optimized the reaction conditions and prepared the manuscript. AW and UC conducted sensitivity and specificity tests using HNB and determined limit of detection, KB conducted sensitivity and specificity tests using calcein and participated in the determination of detection limit; KF conducted sensitivity and specificity tests using Milenia HybriDetect; EM, MP, and KW conducted sensitivity and specificity tests using QuantiFluor; KKG designed primers. All authors participated in the analysis of results. All authors read and approved the final manuscript. All authors gave final approval of the version to be published and are publicly responsible for its contents.

\section{Funding}

This study was supported by the National Institute of Public Health National Institute of Hygiene internal-grant (no. 1/EM/2018). The funder had no role in the study design, data collection, analysis and interpretation and preparation of the manuscript.

\section{Availability of data and materials}

The datasets generated and/or analysed during the current study are available in the GenBank repository, accession number BX248353.

\section{Ethics approval and consent to participate}

Ethical approval was not required for the use of clinical samples because all the investigated isolates were taken as a part of standard care (diagnostic purposes). The samples were not collected for research purposes.

\section{Consent for publication}

Not applicable.

\section{Competing interests}

The authors declare that they have no competing interests.

Received: 17 September 2019 Accepted: 15 April 2020

Published online: 25 April 2020

\section{References}

1. World Health Organization. Diphtheria vaccine: WHO position paper august 2017. Weekly Epidemiol Rec. 2017;92:417-36.

2. European Centre for Disease Prevention and Control (ECDC). Rapid risk assessment: a fatal case of diphtheria in Belgium. 2016. Stockholm: ECDC; 2016a. Available from: http://ecdc.europa.eu/en/publications/Publications/ RRA-Diphtheria-Belgium.pdf. Accessed 27 Aug 2019.

3. Hall AJ, Cassiday PK, Bernard KA, Bolt F, Steigerwalt AG, Bixler D, et al. Novel Corynebacterium diphtheriae in domestic cats. Emerg Infect Dis. 2010;16(4): 688-91

4. Tiwari TSP, Golaz A, Yu DT, Ehresmann KR, Jones TF, Hill HE, et al. Investigations of 2 cases of diphtheria-like illness due to toxigenic Corynebacterium ulcerans. Clin Infect Dis. 2008:46:395-401.
5. Leggett BA, De Zoysa A, Abbott YE, Leonard N, Markey B, Efstratiou A. Toxigenic Corynebacterium diphtheriae isolated from a wound in a horse. Vet Rec. 2010;166:656-8.

6. Tiwari TSP. Diphtheria. In: CDC Yellow Book 2018: Centers for Disease Control and Prevention. New York: Oxfort University Press; 2018.

7. World Health Organization. Diphtheria reported cases. 2018. http://apps. who.int/immunization_monitoring/globalsummary/timeseries/ tsincidencediphtheria.html. Accessed 27 Aug 2019.

8. Meinel DM, Kuehl R, Zbinden R, Boskova V, Garzoni C, Fadini D, et al. Outbreak investigation for toxigenic Corynebacterium diphtheriae wound infections in refugees from Northeast Africa and Syria in Switzerland and Germany by whole genome sequencing. Clin Microbiol Infect. 2016;22(12): 1003 e1-e8.

9. Sane J, Sorvari T, Wideström M, Kauma H, Kaukoniemi U, Tarkka E, et al. Respiratory diphtheria in an asylum seeker from Afghanistan arriving to Finland via Sweden, December 2015. Euro Surveill. 2016;21(2):14-7.

10. Zasada AA. Nontoxigenic highly pathogenic clone of Corynebacterium diphtheriae, Poland, 2004-2012. Emerg Infect Dis. 2013;19(11):1870-2.

11. Zasada AA, Rzeczkowska M. Nontoxigenic Corynebacterium diphtheriae infections, Europe. Emerg Infect Dis. 2019;25(7):1437-8.

12. European Centre for Disease Prevention and Control (ECDC). Gap analysis on securing diphtheria diagnostic capacity and diphtheria antitoxin availability in the EU/EEA. Stockholm: ECDC; 2017. https://ecdc.europa.eu/ sites/portal/files/documents/Diphtheria\%20Gap\%20Analysis\%20final\%2 Owith\%20cover\%20for\%20web.pdf. Accessed 27 August 2019.

13. Efstratiou A, Maple PAC. Manual for the laboratory diagnosis of diphtheria. Copenhagen: WHO Europe; 1994

14. Tanner NA, Zhang Y, Evans TC Jr. Visual detection of isothermal nucleic acid amplification using pH-sensitive dyes. BioTechniques. 2015;58:59-68.

15. Goto M, Honda E, Ogua A, Nomoto A, Hanaki K-I. Colorimetric detection of loop-mediated isothermal amplification reaction by using hydroxyl naphthol blue. BioTechniques. 2009:46:167-72.

16. World Health Organization. Diphtheria tetanus toxoid and pertussis (DTP3) immunization coverage estimates by country. http://apps.who.int/gho/data/ node.main.A827. Accessed 27 August 2019.

17. European Centre for Disease Prevention and Control (ECDC). ECDC. Annual epidemiological report for 2016. Stockholm: ECDC; 2018.

18. Dangel A, Berger A, Konrad R, Bischoff H, Sing A. Geographically diverse clusters of nontoxigenic Conynebacterium diphtheriae infection, Germany, 2016-2017. Emerg Infect Dis. 2018:24(7):1239-45.

19. Bernard KA, Pacheco AL, Burdz T, Wiebe D. Increase in detection of Corynebacterium diphtheriae in Canada: 2006-2019. Can Commun Dis Rep. 2019;45(11):296-301

20. World Health Organization. Diphtheria. Vaccine-Preventable Diseases Surveillance Standards. September 5, 2018. https://www.who.int/ immunization/monitoring_surveillance/burden/vpd/WHO_ SurveillanceVaccinePreventable_04_Diphtheria_R2.pdf?ua=1. Accessed 05 February 2020.

21. Zhao X, Li Y, Park M, Wang J, Zhang Y, He X, et al. Loop-mediated isothermal amplification assay targeting the femA gene for rapid detection of Staphylococcus aureus from clinical and food samples. J Microbiol Biotechnol. 2013;23(2):246-50.

22. Billard-Pomares T, Rouyer C, Walewski V, Badell-Ocando E, Dumas M, Zumelzu C, et al. Diagnosis in France of a Non-Toxigenic tox Gene-Bearing Strain of Corynebacterium diphtheriae in a Young Male Back From Senegal. Open Forum Infect Dis. 2017;4:ofw271.

23. Fuursted K, Søes LM, Crewe BT, Stegger M, Andersen PS, Christensen JJ. Non-toxigenic tox gene-bearing Corynebacterium ulcerans in a traumatic ulcer from a human case and his asymptomatic dog. Microbes Infect. 2015; 17:717-9.

24. Hatano B, Maki T, Obara T, Fukumoto H, Hagisawa K, Matsushita Y, et al. LAMP using a disposable pocket warmer for anthrax detection, a highly mobile and reliable method for anti-bioterrorism. Jpn J Infect Dis. 2010;63: 36-40.

25. LaBarre PD, Geriach J, Wilmoth J, Beddoe A, Singleton JL, Hawkins KR, Weigl BH. Non-instrumented nucleic acid amplification (NINA). Instrument-free molecular diagnostics for low-resource settings. https:/www.who.int/ medical_devices/poster_b03.pdf. Accessed 27 Aug 2019.

26. Hayashida K, Kajino K, Hachaambwa L, Namangala B, Sugimoto C. Direct blood dry LAMP: a rapid, stable, and easy diagnostic tool for human African trypanosomiasis. PLoS Negl Trop Dis. 2015;9:e0003578. 
27. Yan M, Li W, Zhou Z, Pehg H, Luo Z, Xu L. Direct detection of various pathogens by loop-mediated isothermal amplification assays on bacterial culture and bacterial colony. Microb Pathogen. 2017;102:1-7.

28. Dugan L, Bearinger J, Hinckley A, Strout C, Souza B. Detection of Bacillus anthracis from spores and cells by loop-mediated isothermal amplification without sample preparation. J Microbiol Met. 2012;90:280-4.

29. Wong YP, Othman S, Lau YL, Radu S, Chee HY. Loop-mediated isothermal amplification (LAMP): a versatile technique for detection of microorganisms. J Appl Microbiol. 2018;124:626-43.

\section{Publisher's Note}

Springer Nature remains neutral with regard to jurisdictional claims in published maps and institutional affiliations.

Ready to submit your research? Choose BMC and benefit from:

- fast, convenient online submission

- thorough peer review by experienced researchers in your field

- rapid publication on acceptance

- support for research data, including large and complex data types

- gold Open Access which fosters wider collaboration and increased citations

- maximum visibility for your research: over $100 \mathrm{M}$ website views per year

At BMC, research is always in progress.

Learn more biomedcentral.com/submissions 